\title{
Direct predictive speed control of permanent magnet synchronous motor fed by matrix converter
}

\author{
Najmeh Movahhed Neya ${ }^{1}$, Sajad Saberi $^{2}$, Babak Mozafari ${ }^{3}$ \\ ${ }^{1,3}$ Faculty of Electrical Engineering, Science and Research Branch, Islamic Azad University, Tehran, Iran \\ ${ }^{2}$ Faculty of Electrical Engineering, Babol Noshirvani University of Technology, Mazandaran, Babol, Iran
}

\begin{tabular}{|c|c|}
\hline Article Info & ABSTRACT \\
\hline Article history: & This paper proposes a non-cascade -single loop- Direct Speed Control \\
\hline Received May 2, 2020 & $\begin{array}{l}\text { algorithm for surface mounted Permanent Magnet Synchronous Motor } \\
\text { (PMSM) fed by Matrix Converter. The proposed method uses Finite Control }\end{array}$ \\
\hline Revised Jun 10, 2020 & Set Model Predictive Control (FCS-MPC) to manipulate system speed and \\
\hline Accepted Jul 9, 2020 & $\begin{array}{l}\text { currents simultaneously. Also, for better performance of the predictive } \\
\text { method, an observer designed to estimate mechanical torque and other }\end{array}$ \\
\hline Keywords: & $\begin{array}{l}\text { uncertain parameters of the mechanical subsystem as a lumped disturbance. } \\
\text { Simulation results using Matlab/Simulink demonstrate the performance of } \\
\text { proposed algorithm. }\end{array}$ \\
\hline Disturbance Observer & \\
\hline
\end{tabular}

FCS-MPC

Matrix Converter

PMSM drive

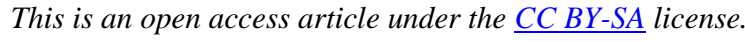

\section{Corresponding Author:}

Corresponding Author,

Faculty of Electrical Engineering,

Science and Research Branch, Islamic Azad University,

Daneshgah Blvd, Simon Bulivar Blvd, Tehran, Iran.

Email: movahhedneya@gmail.com

\section{INTRODUCTION}

In recent years Permanent Magnet Synchronous Motors (PMSM) are getting some real attention due to their high-power density, fast dynamic response, high efficiency and capability of working without gearbox. These characteristics makes PMSM a strong candidate for different applications like wind energy systems, electric vehicles and industrial equipment [1, 2]. Matrix Converter (MC) is a kind of converter that can connect an AC device directly to a three phase AC source by using 9 bidirectional switches [3]. Unlike conventional back to back capacitor-based converters, MCs achieve ac-ac conversion without energy storage link, which helps them to have more reliability, compact size and longer lifetime [3-6].

A typical PMSM drive using matrix converter with three-phase source, input filter and motor is represented in Figure 1. It can be seen that every input phase can connect to an output phase using a switch. To filter input currents and avoid voltage spikes during switching, MCs need an LC filter combined with parasitic resistor. More detail on MC and filter will be given in modeling section. There are different control algorithms for PMSMs but Field Oriented Control (FOC) and Direct Torque Control (DTC) are the most popular methods [7-8]. Interaction between control variables, windup problem, bandwidth limitation due to cascade structure and modulation stage, makes FOC a non-ideal controller choice [9]. DTC uses a lookup table based on switching states to control motor torque directly. Output voltage vectors are not always optimal, as a consequence DTC suffers from high torque and stator flux ripples [10, 11].

Simple treatment of constraints, Multivariable structure and good performance in the presence of nonlinearities make MPC one of the best choices for drive systems [12-13]. There are two main categories 
for MPC, Continuous Control Set MPC (CCS-MPC) and Finite Control Set MPC (FCS-MPC) [9, 14-16]. CCS-MPC needs a modulator to generate gate signals, but FCS-MPC takes advantage of the fact that the number of possible switching states is limited, so it uses the model of the system to predict next state of it for each possible control action and best control action will be chosen by minimizing a cost function [17]. Using cost function helps FCS-MPC to directly control more than one objective at the same time.

Cascade structure is a common strategy for speed/position control of PMSMs, but comparing to current dynamic, mechanical dynamic is sluggish and this difference between time constants enforces the designer to consider longer prediction horizon for DPSC [18]. Moreover, elimination of outer loop controller not only brings stability issues but also decrease system performance and causes steady state error [19]. In [20-22] some methods proposed to control speed of a PMSM fed by a two-level back to back converter directly. This topology eliminates both outer linear controller and modulator.

In this paper we propose a direct predictive speed control for PMSM fed by matrix converter. A new cost function introduced by combining speed dynamic, current dynamic and system constraints to have high performance without cascade structure. To tackle stability issue and high current distortion, due to difference between mechanical and electrical time constants, a current reference designed based on sliding mode concept is added to cost function. This term guarantees outer loop stability and decrease current distortion. Also, to have lower steady state error and better performance, a disturbance observer designed to estimate load torque value and other uncertainties of the mechanical subsystem as a lumped disturbance.

The rest of this paper is organized as follows: In section 2 a model of the system and matrix converter is presented. In section 3 direct predictive speed control cost function described and in section 4 stability proof for current reference part and observer is provided. In section 5 simulation results are discussed to demonstrate the performance of the controller.

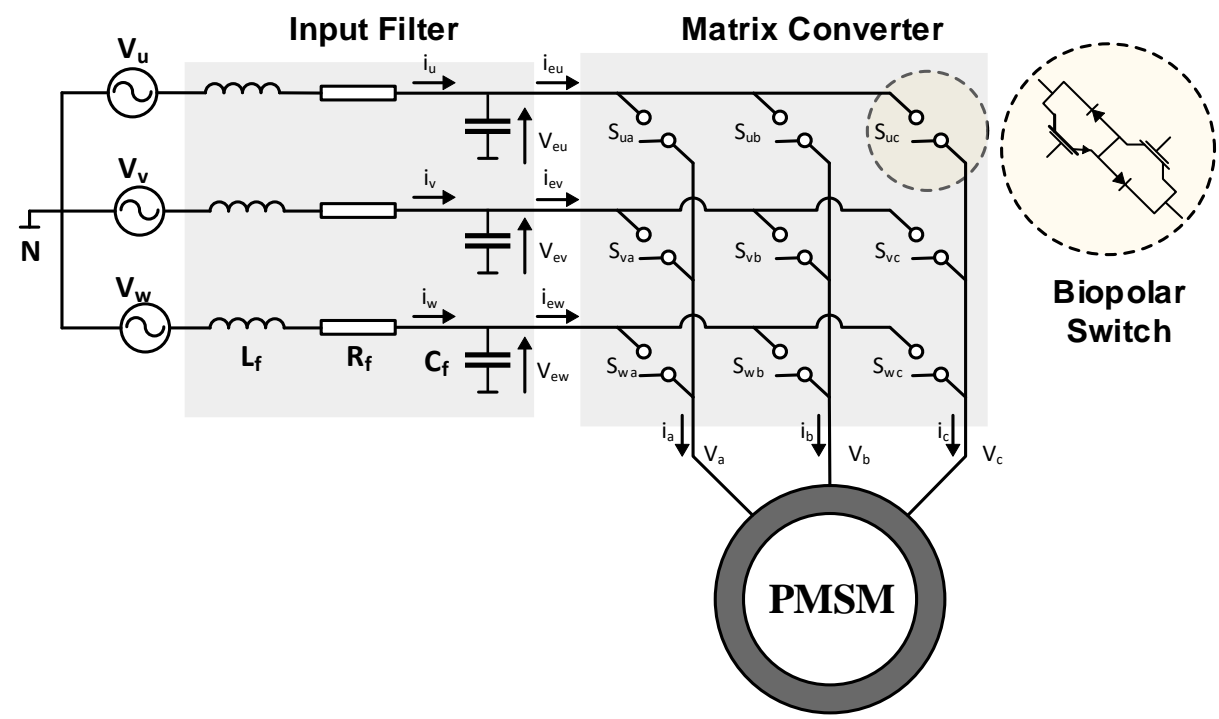

Figure 1. Schematic of a matrix converter drive for PMSM

\section{SYSTEM MODEL}

As it was mentioned, all MPC based control algorithms uses system model to predict next state, so system model has significant impact on this algorithm. In the following section the models for MC, PMSM and input filter are described.

\subsection{Matrix converter model}

Figure 1 shows a $3 \times 3$ MC with 9 bidirectional switches. Each switch is composed of two power transistors and two parallel diodes. The $\mathrm{MC}$ is connected to the three-phase source through the input filter that its inductance i s $L_{f}$, its capacitance is $C_{f}$ and parasitic resistance is $R_{f}$. This filter will eliminate high frequency harmonics in input currents $\left(i_{u}, i_{v}, i_{w}\right)$ and avoid voltage spikes. The mathematical relationship between input and output voltage and current of MC are [23]: 


$$
\underbrace{\left[\begin{array}{c}
v_{a} \\
v_{b} \\
v_{c}
\end{array}\right]}_{v_{o}}=\underbrace{\left[\begin{array}{lll}
S_{u a} & S_{v a} & S_{w a} \\
S_{u b} & S_{v b} & S_{w b} \\
S_{u c} & S_{v c} & S_{w c}
\end{array}\right]}_{T} \underbrace{\left[\begin{array}{c}
v_{e u} \\
v_{e v} \\
v_{e w}
\end{array}\right]}_{v_{i}}, \underbrace{\left[\begin{array}{c}
i_{e u} \\
i_{e v} \\
i_{e w}
\end{array}\right]}_{i_{i}}=\underbrace{\left[\begin{array}{lll}
S_{u a} & S_{u b} & S_{u c} \\
S_{v a} & S_{v b} & S_{v c} \\
S_{w a} & S_{w b} & S_{w c}
\end{array}\right]}_{T^{T}} \underbrace{\left[\begin{array}{c}
i_{a} \\
i_{b} \\
i_{c}
\end{array}\right]}_{i_{o}}
$$

Where $T$ and $T^{T}$ are instantaneous transfer matrix and its transpose respectively and $i=\{u, v, w\}$, $j=\{a, b, c\} . S_{i j}=1$ if the switch that connects $i_{t h}$ input to $j_{t h}$ output phase is ON and $S_{i j}=0$ if the switch is OFF.

Due to the inductive nature of the load, sudden interrupt in current would cause overvoltage that can destroy the component. Also, switches should not short circuit two input phases; because of this restriction, following equation should always be satisfied which reduces the number of possible switchings to 27 .

$$
S_{u y}+S_{v y}+S_{w y}=1 \forall y \in\{a, b, c\}
$$

\subsection{Input filter model}

Input filter shown in Figure 1 is just like an RLC circuit, and can be described by the following state space model [23]:

$$
\dot{\boldsymbol{x}}(t)=\underbrace{\left[\begin{array}{cc}
0 & \frac{1}{C_{f}} \\
\frac{-1}{L_{f}} & \frac{-R_{f}}{L_{f}}
\end{array}\right]}_{\boldsymbol{A}_{C}} \boldsymbol{x}(t)+\underbrace{\left[\begin{array}{cc}
0 & \frac{-1}{C_{f}} \\
\frac{1}{L_{f}} & 0
\end{array}\right]}_{\boldsymbol{B}_{C}} \boldsymbol{u}(t)
$$

Where:

$$
\begin{aligned}
& \boldsymbol{x}(t)=\left[\begin{array}{ll}
\boldsymbol{v}_{i}(t) & \boldsymbol{i}_{s}(t)
\end{array}\right]^{T}, \boldsymbol{u}(t)=\left[\begin{array}{ll}
\boldsymbol{v}_{S}(t) & \boldsymbol{i}_{i}(t)
\end{array}\right]^{T} \\
& v_{s}(t)=\frac{2}{3\left(v_{u}+\boldsymbol{a} v_{v}+\boldsymbol{a}^{2} v_{w}\right)} \\
& \boldsymbol{i}_{s}(t)=\frac{2}{3\left(i_{u}+\boldsymbol{a} i_{v}+\boldsymbol{a}^{2} i_{w}\right)}
\end{aligned}
$$

Where $\boldsymbol{a}=e^{j \frac{2 \pi}{3}}$.

To use $\boldsymbol{i}_{s}$ in FCS-MPC, a discrete model for input filter is needed. Considering a sample time $T_{s p}(5)$ describes this model [24].

$$
\begin{aligned}
& \boldsymbol{x}[k+1]=A_{k} \boldsymbol{x}[k]+B_{k} \boldsymbol{u}[k] \\
& A_{k}=e^{\boldsymbol{A}_{C} T_{s p}}, B_{k}=\int_{0}^{T_{s p}} e^{\boldsymbol{A}_{c}\left(T_{s p}-\tau\right)} \boldsymbol{B}_{c} d \tau
\end{aligned}
$$

To predict $\boldsymbol{i}_{s}[k+1]$ one can use equation (5) or $A_{k}, B_{k}$ and equation (6).

$$
\begin{aligned}
& \boldsymbol{i}_{s}[k+1]=A_{k}(2,1) \boldsymbol{v}_{i}[k]+A_{k}(2,2) \boldsymbol{i}_{s}[k] \\
& +B_{k}(2,1) \boldsymbol{v}_{s}[k]+B_{k}(2,2) \boldsymbol{i}_{i}[k]
\end{aligned}
$$

Using equation (6), a term with relation to $\mathbf{i}_{s}$ can be added to objective function and control using FCS-MPC.

\subsection{PMSM model}

The dynamic model for a PMSM in the $d q$ reference frame can be described as follows:

$$
\begin{aligned}
\frac{d i_{d}}{d t} & =\frac{1}{L_{d}}\left(v_{d}-R_{s} i_{d}+\omega_{e} L_{q} i_{q}\right) \\
\frac{d i_{q}}{d t} & =\frac{1}{L_{q}}\left(v_{q}-R_{s} i_{q}-\omega_{e} L_{d} i_{d}-\omega_{e} \psi_{m g}\right) \\
\frac{d \omega_{e}}{d t} & =\left(\frac{3}{2 J_{m}} Z_{p}^{2} \psi_{m g} i_{q}-\frac{B_{v}}{J_{m}} \omega_{e}+d\right)
\end{aligned}
$$

Whereas $R_{s}$ is the stator resistance, $L_{d}=L_{q}=L_{s}$ are $\mathrm{d}$ and $\mathrm{q}$ axis inductances of the motor, $Z_{p}, J_{m}, B_{v}, \psi_{m g}$ are number of pole pairs, motor inertia, friction coefficient and flux linkage of the permanent 
magnet motor respectively and $d$ is a lumped sum disturbance for load torque and other uncertainties in mechanical subsystem $d=f\left(T_{L}, \Delta J_{m}, \Delta B_{v}\right)$. The value of $d$ has important impact on controller performance, so it will be estimated using an observer in section 5. Also $v_{d}$ and $v_{q}$ are voltage vectors in $d q$ reference frame that are related to switching voltages as Figure 2.

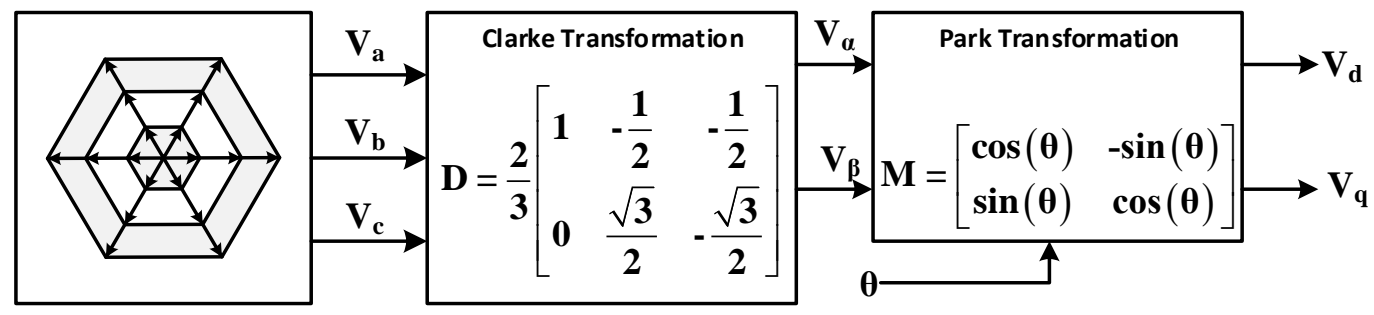

Figure 1. Park-Clarke transformation for dq axis voltages

To predict future values of current and speed, a discrete model of PMSM is needed for FCS-MPC. To reduce calculation burden, a simple discretization method with good performance should be selected. Here the model discretized using forward Euler method [23] as follow, is used, whereas $T_{s p}$ is sampling time.

$$
\begin{aligned}
& i_{d}[k+1]=\left(1-\frac{T_{s p} R_{s}}{L_{s}}\right) i_{d}[k]+\frac{T_{s p}}{L_{s}} v_{d}[k]+T_{s p} \omega_{e}[k] i_{q}[k] \\
& i_{q}[k+1]=\left(1-\frac{T_{s p} R_{s}}{L_{s}}\right) i_{q}[k]+\frac{T_{s p}}{L_{s}} v_{q}[k]-T_{s p} \omega_{e}[k] i_{q}[k]-\frac{T_{s p} \psi_{m g}}{L_{s}} \omega_{e}[k] \\
& \omega_{e}[k+1]=\left(1-\frac{T_{s p} B_{v}}{J_{m}}\right) \omega_{e}[k]+T_{s p}\left(\frac{3}{2 J_{m}} Z_{p}^{2} \psi_{m g} i_{q}[k]+d\right)
\end{aligned}
$$

\section{COST FUNCTION SELECTION}

FCS-MPC takes advantage of the inherent discrete form of the power converters. The control objectives will be predicted for finite number of acceptable switching states of the power converter. The predicted variables will be compared with their reference values through a cost function. The switching state that minimizes the cost function will be applied to the converter to exert the voltage vector to the load in the next control interval, therefore the presence of a modulator is not required [16].

According to the FCS-MPC scheme cost function design is a key point. By proper selection of cost function, FCS-MPC is able to control multiple objectives at the same time. However, proper selection of items and weightings is a challenging task. In this section items of cost function are discussed.

\subsection{PMSM cost term}

The main goal of the controller is to control the speed of PMSM so that the error between predicted speed and measured speed could be a candidate for speed cost.

$$
e_{\omega}=\left(\omega_{e}^{*}-\omega_{e}^{p}\right)^{2}
$$

Where $\omega_{e}^{p}$ is predicted value and $\omega_{e}^{*}$ is the reference value of speed. In contrast to electrical subsystem, mechanical subsystem dynamic is sluggish. So for better performance MPC needs a longer horizon to decrease current and torque distortions when speed error becomes small [18]. We add a current term to speed cost function to not only eliminate longer horizon necessity, but also take care of outer loop stability and current distortion. So the tracking part of cost function should be as follow:

$$
\begin{aligned}
& C_{T}=\lambda_{\omega}\left(\omega_{e}^{*}[k]-\omega_{e}[k+1]\right)^{2}+\lambda_{i q}\left(i_{q}^{*}[k]-i_{q}[k+1]\right) \\
& i_{q}^{*}=\frac{1}{a}\left(\dot{\omega}_{e}^{*}+b \omega_{e}-\hat{d}+k e_{\omega}+k_{s w} \operatorname{sign}\left(e_{\omega}\right)\right)
\end{aligned}
$$

Where $\hat{d}$ is the estimation of disturbance $d$ and $\mathrm{a}, \mathrm{b}$ and $\operatorname{sign}\left(e_{\omega}\right)$ are as follows: 


$$
a=\frac{3}{2 J_{m}} Z_{p}^{2} \psi_{m g}, b=\frac{B_{v}}{J_{m}} \& \operatorname{sign}\left(e_{\omega}\right)= \begin{cases}+1 & e_{\omega}>0 \\ -1 & e_{\omega}<0\end{cases}
$$

Stability proof for $i_{q}^{*}$ in presence of $\hat{d}$ is discussed in section 4 .

\subsection{Constraints cost term}

There are two terms that should be considered, one for current limitation and another one for Maximum Torque Per Ampere (MTPA) criteria [24]:

$$
\begin{aligned}
C_{L} & =\left\{\begin{array}{cc}
\lambda_{L}\left(\sqrt{i_{d}^{2}+i_{q}^{2}}-I_{\max }\right) & \sqrt{i_{d}^{2}+i_{q}^{2}}>I_{\max } \\
0 & \text { o.w }
\end{array}\right. \\
C_{Z_{i}} & =\lambda_{i d}\left(i_{d}+\frac{L_{d}-L_{q}}{\lambda}\left(i_{d}^{2}-i_{q}^{2}\right)\right)^{2} \stackrel{L_{d}=L_{q}}{\longrightarrow} C_{Z_{i}}=\lambda_{i d} i_{d}^{2}
\end{aligned}
$$

\subsection{Input filter cost term}

When we are controlling speed of PMSM using direct MC, control of input current is a very challenging task even by FCS-MPC, but if one needs to control input current as primary control objective, like unit power factor in generative mode, a reactive power term should be added to the cost function. Using equation (6) for grid current, reactive power would be calculated using following equation:

$$
Q^{p}=v_{s \beta} i_{s \alpha}^{p}-v_{s \alpha} i_{s \beta}^{p}
$$

Where $\alpha$ and $\beta$ are real and imaginary part of $\mathbf{v}_{s}$ and $\mathbf{i}_{s}$ in equation (4). So by adding $C_{Z_{i}}$ and reactive term to single term we will have a term called zero term that means this part of cost function should go to zero.

$$
C_{Z}=\lambda_{i d}\left(i_{d}\right)^{2}+\lambda_{Q}\left(Q^{p}\right)^{2}
$$

As in this work, our primary task control is speed of PMSM, $C_{Z}$ does not have reactive power term. By combining $C_{T}$ as tracking term, $C_{L}$ as limitation term and $C_{Z}$ as zero term the cost function will be ready for FCS-MPC.

$$
g=C_{T}+C_{Z}+C_{L}
$$

It is worth mentioning that finding optimal weighting factors when there are constraints in cost function is not a straight task. For this work we used multiple simulations to find weighting factors with good performance of the system.

\section{DISTURBANCE OBSERVER AND CURRENT REFERENCE STABILITY}

Disturbances and uncertainties have high impact on FCS-MPC performance so an accurate disturbance observer can improve proficiency of the system. In this section a disturbance observer designed to estimate load torque value and other uncertainties in mechanical subsystem as a lumped sum disturbance. Let the motor currents and speed be measurable and consider mechanical part of (7) as fallow:

$$
\begin{aligned}
& \dot{\omega}_{e}=a i_{q}-b \omega_{e}+d, a=\frac{3}{2 J_{m}} Z_{p}^{2} \psi_{m g}, b=\frac{B_{v}}{J_{m}} \\
& d=\dot{\omega}_{e}+b \omega_{e}-a i_{q}
\end{aligned}
$$

The design procedure of the disturbance observer is as follow:

Define the disturbance dynamic as:

$$
\dot{\hat{d}}=K(d-\hat{d})
$$


Where $\mathrm{K}$ is a positive constant. To have globally stable estimation without steady state error, an auxiliary variable is defined like the one introduced in [25]:

$z=\hat{d}-K \omega_{e}$

By differentiating (19) and replacing (17) and (18) to new equation we have:

$\dot{z}=\dot{\hat{d}}-K \dot{\omega}_{e}=K(d-\hat{d})-K \dot{\omega}_{e}$

$=K\left(\dot{\omega}_{e}+b \omega_{e}-a i_{q}-\dot{\omega}_{e}\right)-K \hat{d}$

$=K\left(b \omega_{e}-a i_{q}\right)-K \hat{d}$

So disturbance observer can be designed using equation (21):

$\left\{\begin{array}{l}\dot{z}=K\left(b \omega_{e}-a i_{q}\right)-K \hat{d} \\ \hat{d}=z+K \omega\end{array}\right.$

Theorem 1. Using the observer designed with (21) and $i_{q}$ from (11), the speed error, defined as $\widetilde{\omega}_{e}=\omega_{e}^{*}-\omega_{e}$, and the error of disturbance, defined as $\tilde{d}=d-\hat{d}$, will converge to zero asymptotically. Proof. Consider the following Lyapunov function candidate:

$V=\frac{1}{2}\left(\widetilde{\omega}^{2}+\tilde{d}^{2}\right)$

The derivation of $V$ respect to time is:

$\dot{V}=\widetilde{\omega} \dot{\tilde{\omega}}+\tilde{d} \dot{\tilde{d}}$

By substituting (17), (18) and (21) into (23), it can be written that:

$$
\begin{aligned}
\dot{V} & =\widetilde{\omega}\left(\dot{\omega}_{e}^{*}-a i_{q}+b \omega_{e}-d\right)+\tilde{d}(\dot{d}-\dot{\hat{d}}) \\
& =\widetilde{\omega}\left(\dot{\omega}_{e}^{*}-a i_{q}+b \omega_{e}-d\right)+\tilde{d}\left(\dot{d}-\dot{z}-K \dot{\omega}_{e}\right)
\end{aligned}
$$

Using $i_{q}$ from (11), $\dot{z}$ from (20) and considering this fact that in practical engineering we always consider $\dot{d}=0$ [26] we have:

$$
\begin{aligned}
& \dot{V}=\widetilde{\omega}\left(-k \widetilde{\omega}-k_{s w} \operatorname{sign}(\widetilde{\omega})-(d-\hat{d})\right) \\
& +\tilde{d}\left(-K\left(b \dot{\omega}_{e}-a i_{q}\right)+K \hat{d}-K \dot{\omega}_{e}\right) \\
& =-k \widetilde{\omega}^{2}-k_{s w}|\widetilde{\omega}|-\tilde{d} \\
& +\tilde{d}(-K \underbrace{\left(\dot{\omega}_{e}+b \dot{\omega}_{e}-a i_{q}\right)}_{d}+K \hat{d}) \\
& =-k \widetilde{\omega}^{2}-k_{s w}|\widetilde{\omega}|-\tilde{d} \widetilde{\omega}-K \tilde{d}^{2} \\
& \leq-k \widetilde{\omega}^{2}-K \tilde{d}^{2}-k_{s w}|\widetilde{\omega}|+|\tilde{d}||\widetilde{\omega}|
\end{aligned}
$$

Using observer error dynamic $\dot{\tilde{d}}=-K \tilde{d}$, we know that the observer is asymptotically stable and we can assume $|\tilde{d}| \leq D$ for sure. So, the following inequality for derivation of Lyapunov function is satisfied:

$\dot{V} \leq-k \widetilde{\omega}^{2}-K \tilde{d}^{2}-k_{s w}|\widetilde{\omega}|+D|\widetilde{\omega}|$

$=-k \widetilde{\omega}^{2}-K \tilde{d}^{2}-\left(k_{s w}-D\right)|\widetilde{\omega}|$

If we choose a new variable as $\bar{k}_{s w}=k_{s w}-D$ and $k_{s w}>D$ :

$\dot{V} \leq-k \widetilde{\omega}^{2}-K \tilde{d}^{2}-\bar{k}_{s w}|\widetilde{\omega}|$

$\dot{V} \leq-\bar{K}\left(\frac{1}{2} \widetilde{\omega}^{2}+\frac{1}{2} \tilde{d}^{2}\right)=-\bar{K} V$ 
Where $\bar{K}=2 \min \{k, K\}$.

Using the lemma at [26] the solution of $\dot{V} \leq-\bar{K} V$ is:

$V(t) \leq e^{-\bar{K}\left(t-t_{0}\right)} V\left(t_{0}\right)$

So the sliding mode surface converge to zero exponentially and by converging $V$ to zero, error of speed and disturbance estimation goes to zero and the proof is completed.

\section{SIMULATION AND RESULTS}

To prove the effectiveness of the proposed model, a PMSM fed by MC is simulated using MATLAB/Simulink. Parameters of the PMSM are listed in Table 1. Also Figure 3 shows the flowchart of proposed method based on FCS-MPC and V(n) is the $\mathrm{n}^{\text {th }}$ vector of MC voltage in $a b c, d q$ or $\alpha \beta$ reference frame when it is needed.

To show the effectiveness of the proposed method, two other different speed control schemes are used in simulation. First scheme is direct predictive speed control (PSC) without current term that introduced in [18] for back to back converter and other scheme is a control system using PI with anti-windup structure as outer loop controller and FCS-MPC as inner loop current controller.

Remark: One of the drawbacks of FCS-MPC is the time of optimization procedure. Evaluation of cost function for 27 different available voltages is time consuming. Also, in some cases more than 27 calculations are required. The method in [18] used three step horizons for lower torque oscillation and current distortion, that it means three times prediction for each voltage vector are required, so the method needs $27^{3}$ calculations. If one needs to use lower number of voltage vectors in each sampling interval, there is some methods for back to back convertors [27] and matrix converters [28]. In proposed method we used just one step to predict future values of variables and need 27 calculation of cost function however we could use method in [28] to have even lower calculation burden.

Table 1. Parameters of simulation system

\begin{tabular}{cccccc}
\hline Parameter & Value & Unit & Parameter & Value & Unit \\
\hline Stator resistance $R_{s}$ & 1 & $\Omega$ & Viscous damping $\mathrm{B}_{\mathrm{v}}$ & 0.0093 & Nm.s \\
Stator inductance $\mathrm{L}_{\mathrm{s}}, \mathrm{L}_{\mathrm{d}}, \mathrm{L}_{\mathrm{q}}$ & 3.2 & $\mathrm{mH}$ & Filter resistance $\mathrm{R}_{\mathrm{f}}$ & $\Omega$ & 1 \\
Number of pole pairs $\mathrm{Z}_{\mathrm{p}}$ & 4 & & Filter inductance $\mathrm{L}_{\mathrm{f}}$ & $\mathrm{mH}$ & 4 \\
Flux linkage $\psi_{\mathrm{mg}}$ & 0.126 & web & Grid voltage $/ \mathrm{Freq}$ & $\mathrm{V} / \mathrm{Hz}$ & $100 / 50$ \\
Moment of inertia $\mathrm{J}_{\mathrm{m}}$ & 0.126 & $\mathrm{gr} / \mathrm{m}_{2}$ & $\mathrm{I}_{\max }$ & $\mathrm{A}$ & 7 \\
\hline
\end{tabular}

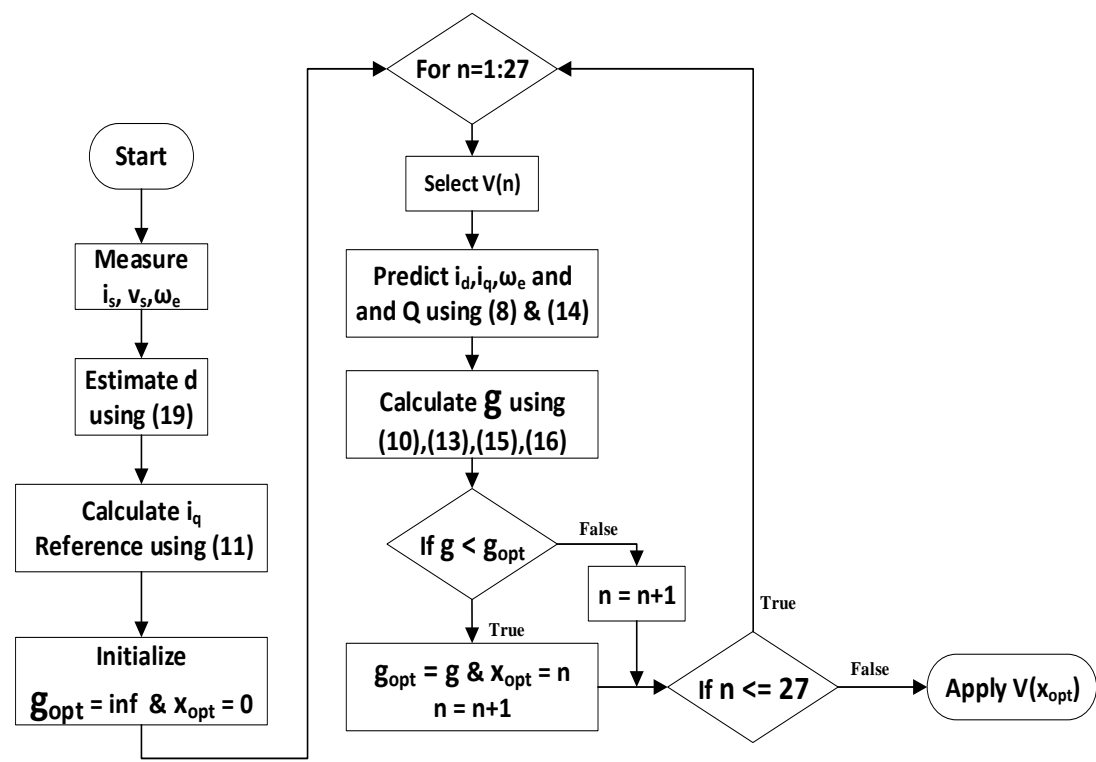

Figure 2. Flowchart of FCS-MPC

Direct predictive speed control of permanent magnet synchronous motor fed by... (Najmeh Movahhed Neya) 
Figure 4 illustrates reference values of speed and load torque during simulation. Also estimated value of load torque using disturbance observer is shown and it can be seen that the observer has very good performance during step changes of load torque and steady state error is zero.

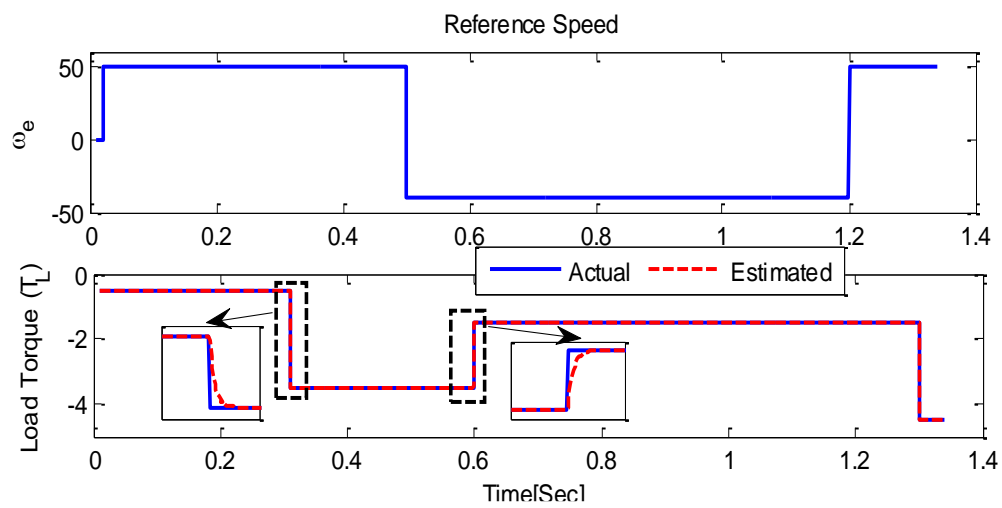

Figure 3: Reference speed, actual and estimated value of load torque

Figure 5 shows reference speed and PMSM speed using 3 different control schemes. It can be seen that two-method based on predictive control have faster dynamic in contrast to cascade structure with PI control. It is worth to mention that PI controller design is optimal and higher gains for higher speeds causes more overshoot in system. Figure 6 illustrates zoomed areas marked with green rectangle in Figure 5 for more details. Subplot (a) shows very low overshoot for proposed method in comparison to other methods even PSC and subplot (b) support this opinion. Subplot (c) shows speed variation during load torque step change and it can be seen that proposed method does not cause oscillation and track the reference speed as fast as possible. Finally, subplot (d) shows a steady state performance and it demonstrates that proposed method has lower steady state error and Table 2 contains Mean Square Error (MSE) values for this part of simulation just for comparison.

During speed transient, current performance is an important issue. With higher speed error weighting in tracking function (10), speed dynamic will be faster but it would cause more current distortion. Current variation during simulation is illustrated in Figure 7 for $i_{q}$. It can be seen that non-cascade structure schemes have more similar behavior and cascade controller with PI have different response.

For more details Figure 8 shows zoomed areas marked with green rectangle in Figure 7 . It is noticeable that all control schemes exert current limitation and PI controller have lower current value in transient mode. Subplot (c) shows step down in q axis current for PSC and proposed method during speed change. It is clear that proposed method has lower undershoot with no oscillation and subplot (d) illustrate this fact during step up change.

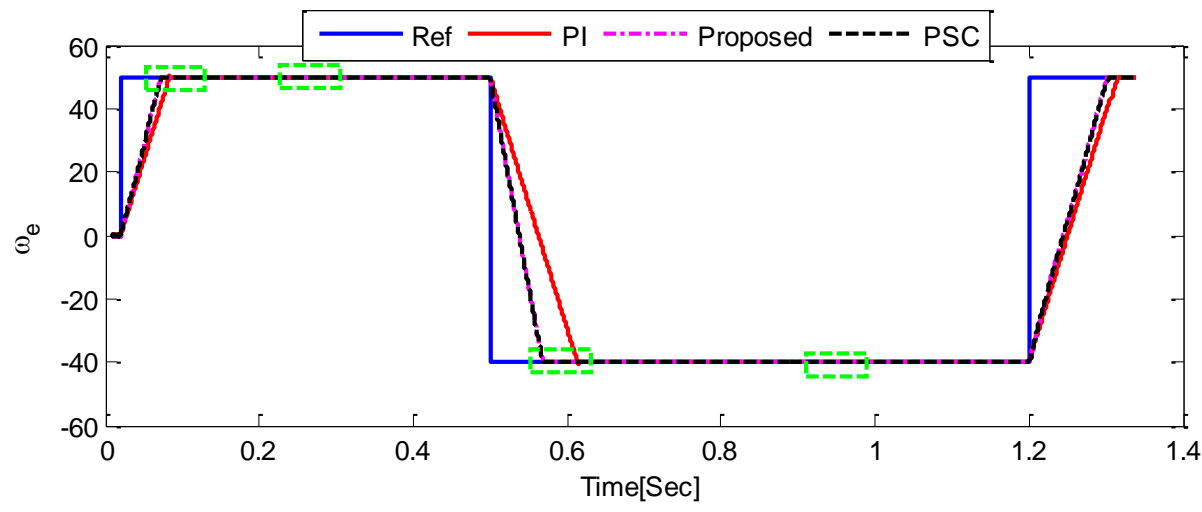

Figure 4: Reference speed and PMSM speed using three different control methods, Predictive Speed control (PSC) [18] (dash, black), PI control as outer loop (solid, red), proposed method (dash-dot, magenta) 

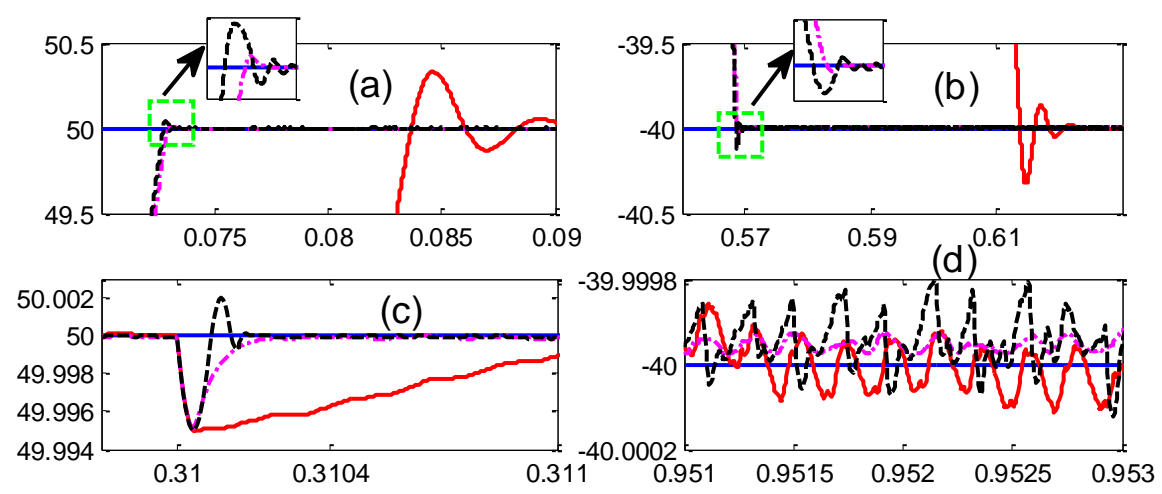

Figure 5. Zoom view of Figure 5 marked with green rectangle

Table 2. Mean square error of PMSM speed for $t=0.951 \mathrm{~s}$ to $\mathrm{t}=0.953$

\begin{tabular}{llll}
\hline & Proposed method & PSC method & PI method \\
\hline MSE & $3.4553 \mathrm{e}-09$ & $2.6177 \mathrm{e}-06$ & $8.7708 \mathrm{e}-07$ \\
\hline
\end{tabular}

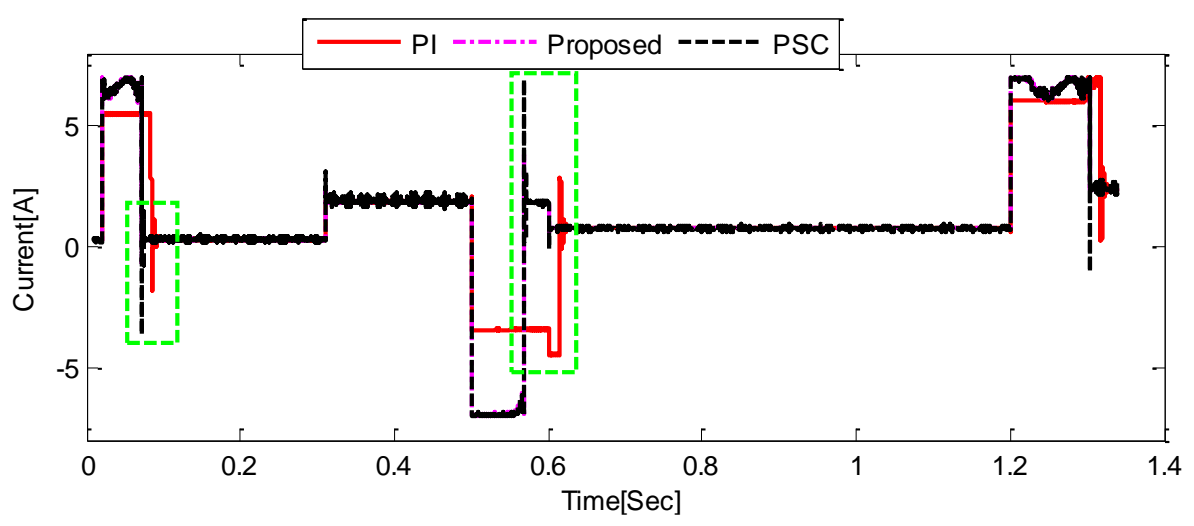

Figure 6. Current transient during simulation time using three different control method, Predictive Speed control (PSC) [18] (dash, black), PI control as outer loop (solid, red), Proposed method (dash-dot, magenta)
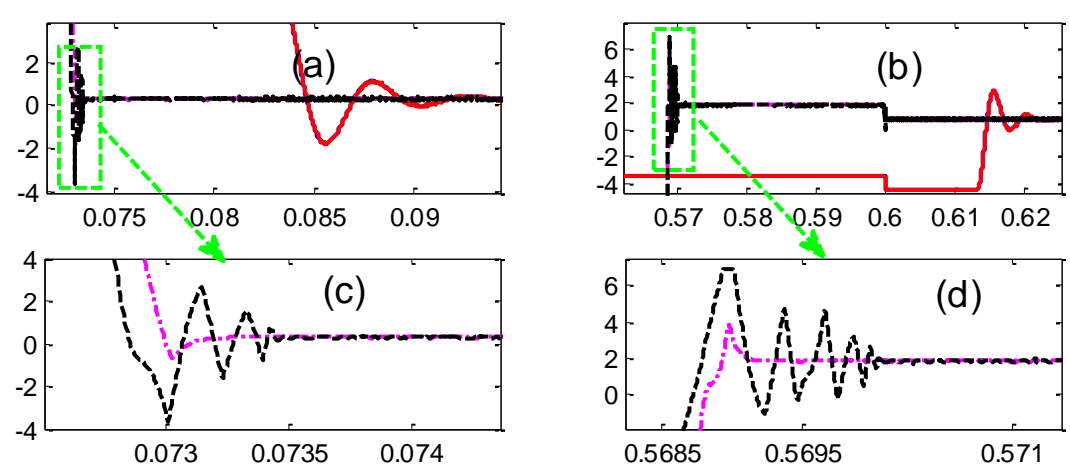

Figure 7: Zoomed view of Figure 7 marked with green rectangle in Figure 7

\section{CONCLUSION}

In this paper a direct predictive speed control for PMSM fed by matrix converter is introduced. A new speed tracking cost function is designed, by combining speed and current dynamics with system constraints to have high performance with low oscillation in speed without cascade structure.To resolve 
stability issue and eliminate high current distortion due to difference between mechanical and electrical time constants, a current reference constructed based on sliding mode concept is been added to tracking term of cost function. This term guarantees outer loop stability and using simulation results it can be seen that this term can decrease current distortion. Also, to have lower steady state error and better performance a disturbance observer is designed to estimate load torque value and other uncertainties of the mechanical subsystem as a lumped disturbance. This observer permits elimination of load torque sensor and increases reliability of the system.

\section{REFERENCES}

[1] Barradi. Y, K. Zazi, M. Zazi, N. Khali, "Control of PMSG based variable speed wind energy conversion system connected to the grid with PI and ADRC approach," International Journal of Power Electronics and Drive Systems (IJPEDS), vol. 10, 1, pp. 128, 2019.

[2] Yuhendri, M., A. Ahyanuardi, and A. Aswardi, "Direct torque control strategy of PMSM employing ultra sparse matrix converter," International Journal of Power Electronics and Drive Systems, vol. 9, no. 1, pp. 64, 2018.

[3] N. Fazli and J. Siahbalaee, "Direct torque control of a wind energy conversion system with permanent magnet synchronous generator and matrix converter," Proceeding of 8th Power Electronics, Drive Systems \& Technologies Conference (PEDSTC 2017), pp. 166-171, 2017.

[4] T. Shi, X. Zhang, S. An, Y. Yan and C. Xia, "Harmonic suppression modulation strategy for ultra-sparse matrix converter," IET Power Electronics, vol. 9, pp. 589-599, 2016.

[5] Naggar H. Saad, Ahmed A. El-Sattar, Mohamed I. Marei, "A current controlled matrix converter for wind energy conversion systems based on permanent magnet synchronous generator," Journal of Electrical Systems and Information Technology, vol. 3, no. 1, pp. 108-118, 2016.

[6] P. B. Shinde and T. N. Date, "Pulse width modulation control of 3 phase AC-AC matrix converter," 2017 International Conference on Computing Methodologies and Communication (ICCMC), Erode, pp. 992-997, 2017.

[7] J. Holtz, "Advanced PWM and predictive control-An overview," IEEE Trans. Ind. Electron., vol. 63, no. 6, pp. 3837-3844, 2016.

[8] Y. Li, Y. Qu, H. Shi and X. Meng, "An optimal switching table for PMSM DTC system using zero voltage vector," 2017 20th International Conference on Electrical Machines and Systems (ICEMS), Sydney, NSW, pp. 1-5, 2017.

[9] Linder, R. Kanchan, P. Stolze, and R. Kennel, "Model-Based Predictive Control of Electric Drives," Göttingen: Cuvillier Verlag, 2010.

[10] C. Zhang, X. Wang, D. Wang, Q. Sun and G. Ma, "Comparative Analysis of Electromagnetic Force Inverter Fed PMSM Drive Using Field Oriented Control (FOC) and Direct Torque Control (DTC)," 2019 22nd International Conference on Electrical Machines and Systems (ICEMS), Harbin, China, pp. 1-4, 2019.

[11] D. Majchrzak and P. Siwek, "Comparison of FOC and DTC methods for a Matrix Converter-fed permanent magnet synchronous motor," 2017 22nd International Conference on Methods and Models in Automation and Robotics (MMAR), Miedzyzdroje, pp. 525-530, 2017.

[12] J. Bocker, B. Freudenberg, A. The, and S. Dieckerhoff, "Experimental comparison of model predictive control and cascaded control of the modular multilevel converter," IEEE Trans. Power Electron., vol. 30, no. 1, pp. 422-430, 2015.

[13] Y. Zhang, Z. Yin, W. Li, X. Tong and Y. Zhong, "Speed Sensorless Model Predictive Control Based on Disturbance Observer for Induction Motor Drives," 2019 IEEE International Symposium on Predictive Control of Electrical Drives and Power Electronics (PRECEDE), Quanzhou, China, pp. 1-4, 2019.

[14] F. Wang, X. Mei, J. Rodriguez and R. Kennel, "Model predictive control for electrical drive systems-an overview," in CES Transactions on Electrical Machines and Systems, vol. 1, no. 3, pp. 219-230, 2017.

[15] E. Garayalde, I. Aizpuru, U. Iraola, I. Sanz, C. Bernal and E. Oyarbide, "Finite Control Set MPC vs Continuous Control Set MPC Performance Comparison for Synchronous Buck Converter Control in Energy Storage Application," 2019 International Conference on Clean Electrical Power (ICCEP), Otranto, Italy, pp. 490-495, 2019.

[16] A. A. Ahmed, B. K. Koh and Y. I. Lee, "A Comparison of Finite Control Set and Continuous Control Set Model Predictive Control Schemes for Speed Control of Induction Motors," in IEEE Transactions on Industrial Informatics, vol. 14, no. 4, pp. 1334-1346, 2018.

[17] O. Sandre-Hernandez, J. Rangel-Magdaleno and R. Morales-Caporal, "A Comparison on Finite-Set Model Predictive Torque Control Schemes for PMSMs," in IEEE Transactions on Power Electronics, vol. 33, no. 10, pp. 8838-8847, 2018.

[18] P. Kakosimos and H. Abu-Rub, "Predictive Speed Control with Short Prediction Horizon for Permanent Magnet Synchronous Motor Drives," in IEEE Transactions on Power Electronics, vol. 33, no. 3, pp. 2740-2750, 2018.

[19] L. Wang, S. Chai, D. Yoo, L. Gan, and K. Ng, "PID and Predictive Control of Electrical Drives and Power Converters Using Matlab/Simulink," Hoboken, NJ, USA: Wiley, 2015.

[20] E. J. Fuentes, C. A. Silva, and J. I. Yuz, "Predictive Speed Control of a Two-Mass System Driven by a Permanent Magnet Synchronous Motor," IEEE Trans. Ind. Electron., vol. 59, no. 7, pp. 2840-2848, 2012.

[21] M. Preindl, and S. Bolognani, "Model Predictive Direct Speed Control with Finite Control Set of PMSM Drive Systems," IEEE Trans. Power Electron., vol. 28, no. 2, pp. 1007-1015, 2013. 
[22] V. Šmídl, Š. Janouš, L. Adam and Z. Peroutka, "Direct Speed Control of a PMSM Drive Using SDRE and Convex Constrained Optimization," in IEEE Transactions on Industrial Electronics, vol. 65, no. 1, pp. 532-542, 2018.

[23] M. Siami, D. Arab Khaburi and J. Rodriguez, "Simplified Finite Control Set-Model Predictive Control for Matrix Converter-Fed PMSM Drives," in IEEE Transactions on Power Electronics, vol. 33, no. 3, pp. 2438-2446, 2018.

[24] T. Inoue, Y. Inoue, S. Morimoto and M. Sanada, "Maximum Torque Per Ampere Control of a Direct TorqueControlled PMSM in a Stator Flux Linkage Synchronous Frame," in IEEE Transactions on Industry Applications, vol. 52, no. 3, pp. 2360-2367, 2016.

[25] W.H. Chen, D.J. Balance, P.J. Gawthrop, J.O. Reilly, "A nonlinear disturbance observer for robotic manipulator," IEEE Trans. Ind. Electronics, vol. 47, no. 4, 2000.

[26] P.A. Ioannou, J. Sun, "Robust Adaptive Control," PTR Prentice-Hall, Upper Saddle River, pp. 7576, 1996.

[27] Z. Zhang, C. M. Hackl and R. Kennel, "Computationally Efficient DMPC for Three-Level NPC Back-to-Back Converters in Wind Turbine Systems With PMSG," in IEEE Transactions on Power Electronics, vol. 32, no. 10, pp. 8018-8034, 2017.

[28] M. Siami, D. A. Khaburi, M. Rivera and J. Rodríguez, "A Computationally Efficient Lookup Table Based FCSMPC for PMSM Drives Fed by Matrix Converters," in IEEE Transactions on Industrial Electronics, vol. 64, no. 10, pp. 7645-7654, 2017. 